Ege Tıp Dergisi / Ege Journal of Medicine 2021; 60 (1): 58-62

\title{
Hipospadias cerrahisi sonrası gelişen meatus darlıklarının tedavisinde meatotomi dilatasyona göre daha başarılı mıdır?
}

Is meatotomy more successful than dilatation in the treatment of meatal stenosis developing after hypospadias surgery?
Ali Tekin
Uygar Bağcı
İlker Zeki Arusoğlu
Hasan Çayırlı

Ege Üniversitesi, Tıp Fakültesi, Cerrahi Tıp Bilimleri Bölümü, Çocuk Cerrahisi Anabilim Dalı, İzmir, Türkiye

\section{ÖZ}

Amaç: Yeni üretra dış meatusunda darlık, hipospadias cerrahisi sonrası en sık görülen komplikasyonlardan biridir. Tedavide meatotomi ve dilatasyon en yaygın kullanılan yöntemlerdir. Bununla birlikte, hangi tedavinin hangi sıra ile kullanılacağı veya tedavi algoritması konusunda yeterli bilgi bulunmamaktadır. Bu çalışmada hipospadias cerrahisi sonrası meatus darlığı gelişmiş olgularda kullanılan tedavi yöntemlerinin etkinlikleri karşılaştırmalı olarak değerlendirilmiştir.

Gereç ve Yöntem: 2009-2019 yılları arasında, daha önce distal hipospadias nedeniyle ameliyat edilen ve meatus darlığı tanısı alarak genel anestezi altında meatotomi veya üretra dilatasyonu ile tedavi edilmiş olguların kayıtları geriye dönük olarak incelendi. Hastaların demografik özellikleri, hipospadias onarımında kullanılan ilk cerrahi yöntem, hipospadias onarımı sonrası meatus darlığı tedavisine kadar geçen süre, tedavi başarısı, nüks darlık tedavisinde kullanılan yöntem kaydedildi. Kontrollerde yakınması tekrar etmeyen olgular başarılı olarak tedavi edilmiş kabul edildi. İstatistiksel analiz için IBM- SPSS Statistics 23 programı yardımı ile Ki-kare, Student T ve Kolmogorov-Smirnov testleri kullanıldı.

Bulgular: Çalışmaya dahil edilen 10 yıllık sürede, distal hipospadias cerrahisi sonrası meatus darlığı gelişen, yaş ortalaması $45,07 \pm 36,60$ ay olan 56 hasta saptandı. Meatus darlığı için yapılan işlem sayısı hasta başına ortalama 1,67 $\pm 0,91$ idi. Hipospadias onarımı ile meatus darlığı için ilk uygulanan tedavi arasındaki ortanca süre sırasıyla; meatotomide 25,97 ay, dilatasyon olgularında 13,72 aydı $(p<0,05)$. İlk tedavi seçeneği olarak dilatasyon uygulanan 42 olguda başarı oranı \%45,2, meatotomi uygulanan 14 olguda ise $\% 78,6$ idi $(p<0,05)$. Nüks olan 10 olgunun tedavisinde dilatasyon $\% 40,16$ olgunun tedavisinde ise meatotomi \% 87,5 başarılı idi (Tablo-3, $p<0,05$ ). İlk darlık tedavisi dilatasyon olan olguların ortalama işlem sayısı $1,83 \pm 0,98$, meatotomi olanların ise $1,21 \pm 0,42$ idi $(p<0,05)$.

Sonuç: Hipospadias cerrahisi sonrası gelişen meatus darlığı ve nükslerinin tedavisinde meatotomi dilatasyona göre daha başarılı bir yöntemdir. Sonuç vermeyen dilatasyonlarda ısrar etmek yerine erken dönemde meatotomi ile daha başarılı sonuç alınabilir.

Anahtar Sözcükler: Meatus darlığı, hipospadias, üretral dilatasyon, meatotomi, çocuk.

\begin{abstract}
Aim: Stenosis in the external orifice of the neo-urethra is one of the most common complications after hypospadias surgery. Meatotomy and dilation are the most commonly used methods in the treatment of these cases. However, there is insufficient data about which treatment will be used in what order or the treatment algorithm. In this study, we aimed to evaluate the effectiveness of treatment methods used in patients with meatal stenosis after hypospadias surgery.
\end{abstract}

\footnotetext{
Sorumlu yazar: Ali Tekin

Ege Üniversitesi, Tıp Fakültesi, Cerrahi Tıp Bilimleri Bölümü,

Çocuk Cerrahisi Anabilim Dalı, İzmir, Türkiye

E-posta: dralitekin@gmail.com

Başvuru tarihi: 06.07.2020

Kabul tarihi: 03.12.2020
} 
Materials and Methods: Hospital records of patients who were operated for distal hypospadias and diagnosed with meatal stenosis and underwent meatotomy or urethral dilatation under general anesthesia were reviewed retrospectively between 2009-2019. The demographic data of the patients, the first surgical method used for hypospadias repair, the duration between the treatment of meatal stenosis and hypospadias repair, the success of the treatment and the method used in the treatment of recurrent stenosis were recorded. Patients whose complaints did not recur during controls were considered to have been successfully treated. Chi-square, Student T, and Kolmogorov-Smirnov tests were used for statistical analysis with help of IBS-SPSS Statistics 23 program.

Results: In the 10-year period included in the study, 56 patients with a mean age of $45.07 \pm 36.60$ months developed meatal stenosis after distal hypospadias surgery. The mean number of procedures for meatal stenosis was $1.67 \pm 0.91$ per patient. The median duration between the hypospadias surgery and the first treatment for meatal stenosis was 25,97 months in meatotomy and 13,72 months in dilatation cases, respectively $(p<0.05)$. The success rate of the first treatment was $45.2 \%$ in 42 patients who underwent dilatation as the first treatment option, and $78.6 \%$ in 14 patients who underwent meatotomy $(p<0.05)$. Dilatation was successful in the $40 \%$ of the recurrent cases, and meatotomy was $87.5 \%$ (Table-3, $p<0.05$ ). According to the initial treatments, the mean number of procedures was $1.83 \pm 0.98$ in patients who underwent dilatation, and $1.21 \pm 0.42$ in those who underwent meatotomy $(p<0.05)$.

Conclusion: Meatotomy is a more successful method than dilatation in the treatment of meatal stenosis and relapses after hypospadias surgery. Instead of insisting on ineffective dilatations, more successful results can be obtained with early meatotomy.

Keywords: Meatal stenosis, hypospadias, urethral dilation, meatotomy, children.

\section{GíRiş}

Yeni üretra dış meatusunda darlık, hipospadias cerrahisinde üretral fistülden sonra en sık görülen komplikasyonlardan biridir $(1,2)$. Hastalarda ince kalibrasyonda, güçlükle, uzun sürede işeme, idrar jetinde çatallanma, spreyleme, işerken veya sonrasında idrar damlatma gibi semptomlarla kendini gösterir (3). Tedavide meatotomi ve dilatasyon en yaygın kullanılan yöntemlerdir. Bununla birlikte, hangi tedavinin hangi sıra ile kullanılacağı veya tedavi algoritması konusunda yeterli bilgi bulunmamaktadır (4). Bu çalışmada hipospadias cerrahisi sonrası meatus darlığı gelişmiş olgularda kullanılan tedavi yöntemlerinin etkinlikleri karşılaştırmalı olarak değerlendirilmiştir.

\section{GEREÇ VE YÖNTEM}

2009-2019 yılları arasında, daha önce distal hipospadias nedeniyle ameliyat edilen ve meatus darlığı tanısı alarak genel anestezi altında meatotomi veya üretra dilatasyonu ile tedavi edilmiş olguların kayıtları geriye dönük olarak incelendi. İnce kalibrasyonla ve güçlükle işeme şikayetleri ile polikliniğe başvurmuş, hipospadias ameliyatı geçmişi olan ve üretra measından $8 \mathrm{Fr}$ sondanın rahatlıkla geçirilemediği olgular meatus darlığı olarak değerlendirildi. Proksimal hipospadias veya travmatik üretra yaralanması nedeni ile gelişen darlıklar çalışmaya dahil edilmedi. Hastaların demografik özellikleri, hipospadias onarımında kullanılan ilk cerrahi yöntem, hipospadias onarımı sonrası meatus darlığı tedavisine kadar geçen süre, tedavi başarısı, nüks darlık tedavisinde kullanılan yöntem kaydedildi. Darlık tedavisinde kullanılan yöntem seçiminde cerrahın kişisel tercihi dışında bir kriter saptanmadı. Üretra dilatasyonu için, kendi tasarımımız olan, distal kısmı erkek üretrasına uygun şekilde eğimli, uçtan geriye doğru genişleyen metal üretra bujileri (Bahadır, İstanbul, Şekil-1) kullanıldı. Dilatasyon, 6 Fr'den başlayarak yaşa göre en az $10 \mathrm{Fr}$, en çok 16 Fr'e kadar çıkılarak (Tablo-1) uygulandı. Meatotomi ise, üretra meası ventralindeki, glanüler neoüretranın distal bölümünün ventral duvarını oluşturan skarlı, inelastik dokunun, düz klemp ile ezilmesi sonrası, "V" şeklinde 2-4 milimetre uzunluğunda eksizyonu ve ardından $7 / 0$ polidiaksanon veya $8 / 0$ polyglactin sütür ile yara kenarlarının sütüre edilmesi şeklinde uygulandı (Şekil-2 ve Şekil-3). Günübirlik cerrahi olarak, genel anestezi altında uygulanan işlem sonrası hastalar işemeleri gözlendikten sonra aynı gün taburcu edildi. Olgular işlem sonrası 15. gün, 1. ay, 6 . ay ve sonrasında yıllık kontrollere çağırıldı. Kontrollerde yakınması tekrar etmeyen olgular başarılı olarak tedavi edilmiş kabul edildi. İstatistiksel analiz için IBM- SPSS Statistics 23 programı yardımı ile Ki-kare, Student $\mathrm{T}$ ve Kolmogorov-Smirnov testleri kullanıldı. Hasta yakınlarından bilgilendirilmiş onam ve Ege Üniversitesi Tıbbi Araştırmalar Etik Kurulundan 20-7T/68 nolu kararla etik kurul onayı alındı. 
Tablo-1. Yaşa göre maksimum dilatatör genişliği.

\begin{tabular}{ll}
\hline Yaş & Dilatatör genişliği \\
\hline $0-2$ yaş & $10 \mathrm{~F}$ \\
$2-4$ yaş & $12 \mathrm{~F}$ \\
$4-10$ yaş & $14 \mathrm{~F}$ \\
$10-17$ yaş & $16 \mathrm{~F}$ \\
\hline
\end{tabular}

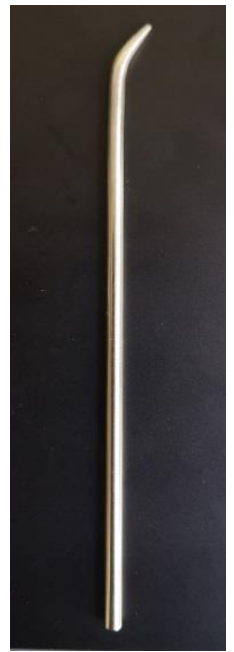

Şekil-1. Üretral dilatatör.

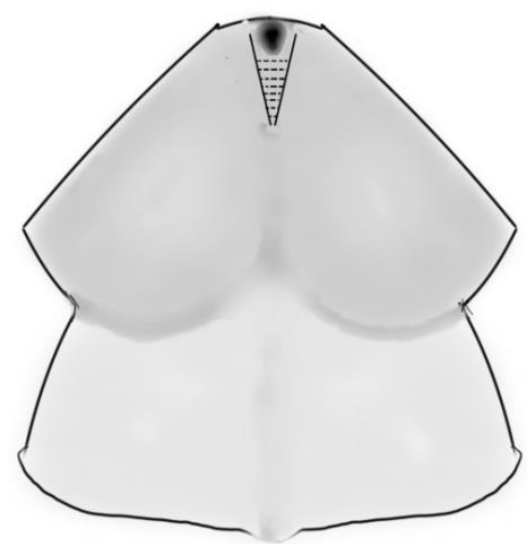

Şekil-2. Üretral mea ventralindeki skarl, inelastik dokunun, düz klemp ile ezilmesi sonrası, $V$ şeklinde 2-4 milimetre uzunluğunda eksizyon uygulandı.

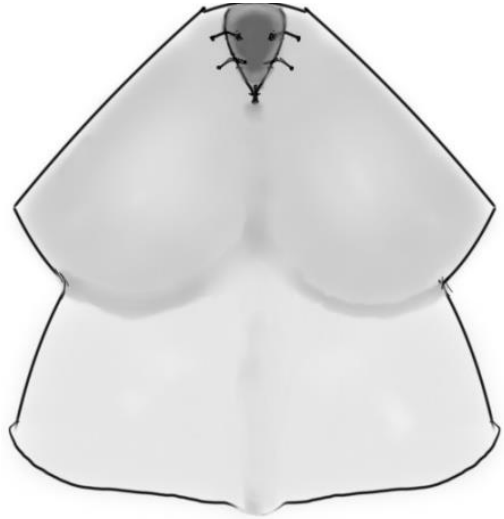

Şekil-3. Doku eksizyonunun ardından 7/0 polidiaksanon veya $8 / 0$ polyglactin sütür ile yara kenarları sütüre edildi.

\section{BULGULAR}

Çalışmaya dahil edilen 10 yıllık sürede, distal hipospadias cerrahisi sonrası meatus darlığı gelişen 56 hasta saptandı. Yaş ortalaması sırasıyla ilk tedavisi dilatasyon olan olgularda $52,84 \pm 28,20$, meatotomi olan olgularda ise $88,15 \pm 39,00$ idi. Gruplar arasında yaş açısından anlamlı bir farklılık yoktu. Tüm hastalar hipospadias tedavisi için tübülarize insize plak üretroplasti (TIPU) yöntemi ile ameliyat edilmişti. Olguların meatus darlığı tedavi yöntemine göre dağılımı Tablo-2'de gösterilmiştir. Meatus darlığı için yapılan işlem sayısı hasta başına ortalama $1,67 \pm 0,91$ idi. Ameliyat tarihi ile meatus darlığı için ilk uygulanan tedavi arasındaki ortanca süre; meatotomide 25,97 ay, dilatasyon olgularında 13,72 aydı $(p<0,05)$. Illk tedavi seçeneği olarak dilatasyon uygulanan 42 olguda başarı oranı $\% 45,2$, meatotomi uygulanan 14 olguda ise $\% 78,6$ idi $(p<0,05)$. İlk darlık tedavisi dilatasyon olan olguların ortalama işlem sayısı $1,83 \pm 0,98$, meatotomi olanların ise $1,21 \pm 0,42$ idi $(p<0,05)$. Nüks olan 10 olgunun tedavisinde dilatasyon $\% 40,16$ olgunun tedavisinde ise meatotomi $\% 87,5$ başarılı idi $(p<0,05)($ Tablo- 3$)$.

Tablo-2. Meatus darlığı nedeni ile tedavi edilen olgular.

\begin{tabular}{lllll}
\hline İlk işlem türü (n) & Ortalama yaş (ay) & $\begin{array}{l}\text { İlk işleme kadar geçen } \\
\text { süre }(\mathbf{a y})\end{array}$ & Başarı & $\begin{array}{l}\text { Ortalama işlem } \\
\text { sayısı }\end{array}$ \\
\hline Dilatasyon (42) & $52,84 \pm 28,20$ & $13,72 \pm 13,80$ & $\% 45,2$ & 1,83 \\
Meatotomi (14) & $88,15 \pm 39,00$ & $25,97 \pm 19,84^{*}$ & $\% 78,6^{*}$ & $1,21^{*}$ \\
${ }^{*} \mathrm{p}<0,05$ & & & & \\
\hline
\end{tabular}


Tablo-3. Meatus darlığı nüksü nedeni ile tedavi edilen olgular.

\begin{tabular}{ll}
\hline İşlem türü $(\mathbf{n})$ & Başarı \\
\hline Dilatasyon (10) & $\% 40$ \\
Meatotomi (16) & $\% 87,5^{\star}$ \\
${ }^{*} \mathrm{p}<0,05$ & \\
\hline
\end{tabular}

\section{TARTIŞMA}

Hipospadias cerrahisi sonrası gelişen meatus darlığı komplikasyonunu azaltmak için çeşitli cerrahi modifikasyonlar önerilse de, darlık gelişimi halen kayda değer oranlarda gözlenmektedir (3). Hipospadias cerrahisi sonrası meatus darlığı gelişimi, yeni üretra measının olması gerektiğinden daha distale yapılması, üretra oluşturulurken ince stent veya kateter kullanımı, glans kanatlarının sıkıca yaklaştırılması gibi cerrahi tekniği ile ilgili sebeplere bağlı olabilir (5). Bu olgularda özellikle TIPU yöntemi sonrası bazı araştırmacılar günlük meatal dilatasyon önerse de diğer araştırmacılar bu uygulamayı gereksiz bulmuşlardır $(6,7)$. Serimizde günlük dilatasyon uygulanan hasta yoktur ve merkezimiz günlük dilatasyonu önermemektedir. Hipospadias cerrahisi sonrası meatus darlıklarının balanitis xerotica obliterans (BXO) nedeni ile de gelişebileceği gösterilmiştir (8). Tedavisi farklı olduğu için çalışmamıza BXO tanılı hastalar dahil edilmemiştir. Mesane greftinin glans içine yerleştirilmesi de daralmada suçlanmıştır ve bu nedenle bu greftin kullanımından büyük oranda vazgeçilmiştir (9). Bilinen tüm bu nedenlerin gösterilemediği, ancak buna rağmen meatus darlığı gelişen serimizdeki gibi olgular görülebilmektedir.

Üretra measında darlık tanısının ölçü veya kalibrasyon ile konulması oldukça güçtür. Bazı araştırmacılar bir sınır değer vermeye çalışsa da, görsel olarak meatus açıklığı ortalamanın altında olan çocuklarda da işeme ile ilgili bir yakınmanın olmayabileceği gösterilmiştir (10). Bu nedenle poliklinikte meatus darlığı tanısını fizik bakı yanında, klinik bulgular ve yakınmalar eşliğinde koymak gerekir. Özellikle işemenin gözlenmesi, video kayıtlarının izlenmesi tanıya yardımcı olur.

Gelişen meatus darlıkları için sıklıkla dilatasyon yapıldığı belirtilse de bu amaçla en belirgin öneri Kim ve ark. tarafından yapılan meatotomidir (11). $\mathrm{Bu}$ çalışmada yeni oluşturulan üretra boyunun ventral meatotomi ile kısalmasına vurgu yapılarak, dorsal meatotomi tercih edilmiştir. Snodgrass, anektodal olarak dorsal meatotomi uygulandığından bahsetmiştir (4). Çalışmamızda dilatasyon veya meatotomi işlemi öncesi ve sonrası üretra boyu ölçülmediği için bu konuda bilimsel bir tartışma yapılamayacak olsa da özellikle meatotomi sonrası beklenen kısalmanın anlamlı olacağını düşünmemekteyiz. Ayrıca ventralde zaten sütüre edilmiş bir yara hattı var iken, dorsale ikinci bir kesi ile yara yüzeyi ve muhtemel skar oluşturmak ileri darlık gelişmesi riskini arttırabilir.

Üretral dilatasyon özellikle poliklinik şartlarında, olgunun ebeveynleri tarafından veya kendi kendine yapabileceği bir işlem olarak görülmüş ve bu nedenle meatus darlığı tedavisi ve proflaksisinde önerilmiştir (7). Ancak bu yöntem ağrılı olduğu için rutin kullanıma girmemiştir. Olgularımızda dilatasyon işlemi metal bujilerle yapıldığı ve ağrılı olacağı için genel anestezi altında yapılması tercih edilmiştir. Üretral dilatasyonun yapılacağı maksimum dilatatör genişlikleri yaşa göre olması gereken meatal genişlikler düşünülerek yapılmıştır $(12,13)$.

Meatotomi, meatal stenoz tedavisinde önerilen bir yöntem olsa da yöntemi ve başarısı konusunda çok az literatür bilgisi vardır (14). Olgularımıza ventral yüzden yarık şeklinde açıklık kalacak kadar meatotomi yapılarak $8 / 0$ veya $7 / 0$ emilebilir dikişlerle kesi kenarları sütüre edilmiştir. Dilatasyonla açılan darlıklarda düzensiz yara kenarları ve yırtılma oluştuğundan, sekonder iyileşme ile tekrar daralma oluşabilir. Emilebilir dikişlerle yara kenarlarını yaklaştırmanın, açıklığı koruma açısından destekleyici ve yeniden darlık gelişimini önleyici olduğunu düşünmekteyiz. Bu nedenle, lokal anestezik kremle ayaktan meatotomiyi uygulamamaktayız.

Çalışmamızda meatus darlığında ilk tedavi yöntemi olarak meatotomi seçildiğinde başarı oranının anlamlı derecede daha yüksek olduğu görülmektedir. İkinci kez meatus darlığı saptanan olgularda da meatotomi dilatasyondan daha başarılı olmuştur. Bu farkı striktüre neden olan faktörlerin sürüyor olmasına bağlayabilsek de histolojik bir çalışma yapılmadığından sadece sübjektif bir yorum olarak kalmaktadır. Bununla 
birlikte ilk işlem olarak meatotomi seçildiğinde toplam cerrahi ve dolayısı ile anestezi sayısı da azalmaktadır.

Serimizdeki olgularda tedavi seçeneği olarak daha geç gelişen stenozlar için öncelikle meatotomiyi tercih ettiğimiz görülmektedir. Nüksle başvuran vakalarda dilatasyon başarısının düşük olması da darlığın ortaya çıkması ile hipospadias cerrahisi arasında geçen sürenin artmış olması ile açıklanabilir.

Değerlendirmenin retrospektif oluşu, ofis dilatasyon ve ofis meatotomi (ayaktan lokal anestezi ile) tekniklerini içermemesi, histolojik bakı yapılmamış olması çalışmanın zayıf yönleridir. Bu yöntemleri de içeren prospektif çalışmalarla sonuçlarımız desteklenebilir.

\section{SONUÇ}

Hipospadias cerrahisi sonrası gelişen meatus darlığı ve nükslerinin tedavisinde meatotomi dilatasyona göre daha başarılı bir yöntemdir. Sonuç vermeyen dilatasyonlarda ısrar etmek yerine erken dönemde meatotomi ile daha başarılı sonuç alınabilir.

\section{Çıkar çatışması}

$\mathrm{Bu}$ çalışma sırasında, yapılan araştırma konusu ile ilgili doğrudan bağlantısı bulunan herhangi bir ilaç firmasından, tıbbi alet, gereç ve malzeme sağlayan ve/veya üreten bir firma veya herhangi bir ticari firmadan, çalışmanın değerlendirme sürecinde, çalışma ile ilgili verilecek kararı olumsuz etkileyebilecek maddi ve/veya manevi herhangi bir destek alınmamıştır.

Bu çalışma ile ilgili olarak yazarların ve/veya aile bireylerinin çıkar çatışması potansiyeli olabilecek bilimsel ve tıbbi komite üyeliği veya üyeleri ile ilişkisi, danışmanlık, bilirkişilik, herhangi bir firmada çalışma durumu, hissedarlık ve benzer durumları yoktur.

Çalışma hazırlanırken; veri toplanması, sonuçların yorumlanması ve makalenin yazııması aşamalarında herhangi bir çıkar çatışması alanı bulunmamaktadır.

\section{Kaynaklar}

1. Agrawal K, Misra A. Unfavourable results in hypospadias. Indian J Plast Surg 2013; 46 (2): 419-27.

2. Snodgrass WT. Tubularized incised plate hypospadias repair: Indications, technique, and complications. Urology 1999; 54 (1): 6-11.

3. Pat Malone. Meatal Stenosis and Urethral Strictures After Hypospadias Surgery. In: Hadidi AT, Azmy AF. Hypospadias Surgery. Berlin, Springer Berlin Heidelberg; 2004: 294-300.

4. Snodgrass WT, Bush NC. Hypospadiology. 1st ed. Texas, Operation Happenis, Inc.; 2015:138-48.

5. Snodgrass WT, Nguyen MT. Current technique of tubularized incised plate hypospadias repair. Urology. 2002 Jul 1; 60 (1): 157-62.

6. Lorenzo AJ, Snodgrass WT. Regular dilatation is unnecessary after tubularized incised-plate hypospadias repair. BJU Int. 2002; 89 (1): 94-7.

7. Radojicic ZI, Perovic S v., Stojanoski KDJ. Calibration and dilatation with topical corticosteroid in the treatment of stenosis of neourethral meatus after hypospadias repair. BJU International 2006; 97 (1): 166-8.

8. Sultan M, El-Shazly M, Elsherif E, Younes S, Selim M. Role of urethral plate and fossa navicularis biopsies in the detection of balanitis xerotica obliterans in boys undergoing redo hypospadias repair. Arab J Urol 2017; 15 (4): 326-30.

9. Ransley PG, Duffy PG, Oesch IL, van Oyen P, Hoover D. The use of bladder mucosa and combined bladder mucosa/preputial skin grafts for urethral reconstruction. J Urol 1987;138 (4 II): 1096-8.

10. Joudi M, Fathi M, Hiradfar M. Incidence of asymptomatic meatal stenosis in children following neonatal circumcision. J Pediatr Urol 2011 Oct 1; 7 (5): 526-8.

11. Kim KS, King LR. Method for correcting meatal stenosis after hypospadias repair. Urology 1992 Jun;39 (6): 545-6.

12. Litvak AS, Morris JA, McRoberts JW. Normal size of the urethral meatus in boys. J Urol 1976; 115 (6): $736-7$.

13. Orkiszewski M, Madej J. The meatal/urethral width in healthy uncircumcised boys. J Pediatr Urol 2009; 6: 130-3.

14. Godley SP, Sturm RM, Durbin-Johnson B, Kurzrock EA. Meatal stenosis: A retrospective analysis of over 4000 patients. J Pediatr Urol 2015 Feb 1; 11 (1): 38. 